\title{
Immunochemical studies of the lipopolysaccharides of Hafnia alvei PCM 1219 and other strains with the 0 -antigens containing D-glucose 1-phosphate and 2-deoxy-2-[(R)-3-hydroxybutyramido]-D-glucose
}

\author{
Ewa Katzenellenbogen ${ }^{1}$, Nina A. Kocharova ${ }^{2}$, Agnieszka Korzeniowska-Kowal ${ }^{1}$, \\ Andrzej Gamian ${ }^{1,3}$, Maria Bogulska ${ }^{1}$, Bernadeta Szostko ${ }^{1}$, Alexander S. Shashkov ${ }^{2}$ \\ and Yuriy A. Knirel ${ }^{2}$ \\ ${ }^{1}$ Institute of Immunology and Experimental Therapy, Polish Academy of Sciences, Wrocław, Poland \\ 2 N. D. Zelinsky Institute of Organic Chemistry, Russian Academy of Sciences, Moscow, Russian Federation \\ 3 Department of Medical Biochemistry, Wrocław Medical University, Wrocław, Poland
}

Received: 2007.10.10, Accepted: 2008.06.30, Published online first: 2008.10 .06

\begin{abstract}
Introduction: Hafnia alvei is the only species of the genus Hafnia, which belongs to the family of Enterobacteriaceae. These Gram-negative bacteria are commonly distributed in the natural environment and are often the cause of human opportunistic infections. Their lipopolysaccharides (LPSs) are important surface antigens which are responsible for the serological specificity and numerous cross-reactions with other enterobacterial genera. So far, 29 different O-polysaccharide (OPS, O-antigen) structures in Hafnia LPSs have been established and for some of them the molecular basis of the serological activity has been elucidated.

Materials and Methods: OPS from H. alvei strain PCM 1219 was obtained by mild acid hydrolysis of the LPS followed by gel permeation chromatography of carbohydrate material on Sephadex G-50 column. The polysaccharide structure was determined using chemical methods as well as ${ }^{13} \mathrm{C}$ NMR and ${ }^{1} \mathrm{H}$ NMR spectroscopy. For serological studies, SDS-PAGE, immunoblotting, and passive hemagglutination tests were used.

Results: The serological studies revealed a cross-reactivity of the LPSs of H. alvei PCM 1219 and a group of $H$. alvei strains with an O-antigen containing D-glucose 1-phosphate and $[(R)$-3-hydroxybutyramido]-D-glucose. The following structure of the OPS was established: $\rightarrow 2)-\alpha-D-G l c p-\left(1-P_{4}-6\right)-\alpha-D-G l c p$ NAcyl- $(1 \rightarrow 4)-\alpha-D-G a l p N A c-(1 \rightarrow 3)-\beta-D-G a l p N A c-(1 \rightarrow$

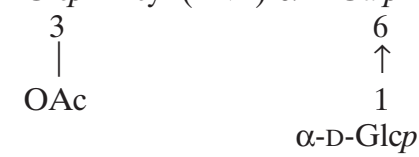

where Acyl stands for $(R)$-3-hydroxybutyryl and the degree of $O$-acetylation is $\sim 70 \%$. The structure of the core oligosaccharide was found to be typical of the genus Hafnia.

Conclusions: Based on the OPS structure and serological results it was concluded that $H$. alvei strain PCM 1219 should be classified in the same serogroup as the H. alvei type strain ATCC 13337 and five other strains containing D-glucose 1-phosphate and 2-deoxy-2-[(R)-3-hydroxybutyramido]-D-glucose in their O-antigens.
\end{abstract}

Key words: Hafnia alvei, enterobacteria, O-antigen, lipopolysaccharide, bacterial polysaccharide structure, serological cross-reactivity.

Abbreviations: COSY - correlation spectroscopy, OPS - O-polysaccharide, HMQC - heteronuclear multiple-quantum coherence, HSQC - heteronuclear single-quantum coherence, LPS - lipopolysaccharide, ROESY - rotating frame NOE spectroscopy, TOCSY - total correlation spectroscopy.

Corresponding author: Ewa Katzenellenbogen, Institute of Immunology and Experimental Therapy, Polish Academy of Sciences, Weigla 12, 53-114 Wrocław, Poland, fax: +48 71 337-13-82, e-mail: katzenel@iitd.pan.wroc.pl 


\section{INTRODUCTION}

Hafnia microorganisms are typical representatives of the Enterobacteriaceae family and show close serological relationship with such species and genera as Escherichia coli, Enterobacter cloaceae, Salmonella, Klebsiella, and Citrobacter. The genus Hafnia contains only one species, Hafnia alvei, which is a rarely occurring but important opportunistic human pathogen found in many incidents of nosocomial infection [11, 18, 23]. In the natural environment, Hafnia bacteria widely exist in soil, flowing waters, and sewage. According to the serological classification, the genus Hafnia includes 39 O-serotypes [1]. Chemical studies carried out on Hafnia lipopolysaccharides (LPSs), besides their purely scientific significance, can explain the molecular basis of the serological classification of Hafnia $[14,15,21]$. Structural investigation of O-specific polysaccharides (O-antigens) will also help to understand the serological cross-reactivity of Hafnia with different species of Enterobacteriaceae. Most of the polysaccharides examined are neutral or acidic hexosaminoglycans, some of them containing rarely occurring monosaccharides and non-sugar components, such as 4-amino-4,6-dideoxyhexoses, 3-amino-3,6-dideoxyhexoses, 6-deoxy-D-talose, $\mathrm{N}$-acetylneuraminic acid, D-allothreonine, glycerol phosphate, arabinitol phosphate, phosphoethanolamine, $\mathrm{N}$-linked 3-hydroxybutanoyl, and formyl groups [21]. Several polysaccharides with phosphodiester linkages resemble the teichoic acids of Gram-positive bacteria. The repeating units of $H$. alvei O-polysaccharides (OPSs) are linear or branched oligosaccharides which range in size from two [17] to eight [7, 13] monosaccharide residues, the most common being penta- or hexa-saccharides.

Here we report the structure of the OPS isolated from H. alvei strain PCM 1219, which belongs to a group of strains represented by the type strain ATCC 13337 , which contain $[(R)$-3-hydroxybutyramido]-D-glucose in their O-antigens.

\section{MATERIALS AND METHODS}

\section{Bacterial strains, isolation and degradation of the LPS}

H. alvei strain PCM 1219 from the collection of the Institute of Immunology and Experimental Therapy (Wrocław, Poland) was cultivated in a liquid medium with aeration at $37^{\circ} \mathrm{C}$ for $24 \mathrm{~h}$ as described earlier [22]. The LPS was isolated from dry bacterial mass by phenol-water extraction [28] and purified by gel-permeation chromatography on Sepharose 2B as described [20]. LPS from other strains were obtained earlier [21]. The LPS from $H$. alvei 1219 was degraded with aq $1 \%$ HOAc at $100^{\circ} \mathrm{C}$ for $45 \mathrm{~min}$ or with $0.1 \mathrm{M}$ sodium acetate buffer, $\mathrm{pH} 4.2$, at $100^{\circ} \mathrm{C}$ for $4 \mathrm{~h}$, the lipid A precipitate was removed by centrifugation, and the carbohydrate portion was fractionated by gel-permeation chromatography on a column $(2 \times 100 \mathrm{~cm})$ of Sephadex G-50 equilibrated with $0.05 \mathrm{M}$ pyridine/acetic acid, $\mathrm{pH} 5.7$, to give fractions $\mathrm{P}_{1}$ (subfractions 1-5), $\mathrm{P}_{2}$ (subfractions 6,7), $\mathrm{P}_{3}$ (fraction 8), and $\mathrm{P}_{4}$ (fraction 9 ) with yields of $41,12.8$, 30.8 , and $15.4 \%$, respectively. Fraction $\mathrm{P}_{3}$ (core oligosaccharide) was further fractionated on a Bio-Gel $\mathrm{P}-2$ column $(2 \times 100 \mathrm{~cm})$ using the same buffer to give fractions $\mathrm{P}_{3 \mathrm{a}}$ and $\mathrm{P}_{3 \mathrm{~b}}$. Elution was monitored by the phenol-sulfuric acid method [4]. Dephosphorylation of the OPS (fraction $\mathrm{P}_{1}$ ) and core oligosaccharide (fraction $\mathrm{P}_{3 \mathrm{~b}}$ ) was performed with aqueous $48 \% \mathrm{HF}$ at $4^{\circ} \mathrm{C}$ for $48 \mathrm{~h}$. $O$-deacetylation of the OPS was carried out by treatment with $12 \%$ aqueous ammonia at $20^{\circ} \mathrm{C}$ for $16 \mathrm{~h}$.

\section{Chemical analyses}

For sugar analysis, the OPS and core oligosaccharide were hydrolyzed with $2 \mathrm{M} \mathrm{CF}_{3} \mathrm{CO}_{2} \mathrm{H}\left(120^{\circ} \mathrm{C}, 2 \mathrm{~h}\right)$ or 10 $\mathrm{M} \mathrm{HC1}\left(80^{\circ} \mathrm{C}, 30 \mathrm{~min}\right)$. D-GalN was identified after hydrolysis of the OPS with $4 \mathrm{M} \mathrm{HCl}$ at $105^{\circ} \mathrm{C}$ for $18 \mathrm{~h}$. The monosaccharides were reduced with $\mathrm{NaBH}_{4}$, peracetylated as described [24], and the resultant alditol acetates were analyzed by GLC-MS using a Hewlett-Packard 5971A chromatograph equipped with an HP-1 glass capillary column $(12 \mathrm{~m} \times 0.2 \mathrm{~mm})$ and a temperature program of $150 \rightarrow 270^{\circ} \mathrm{C}$ at $8^{\circ} \mathrm{C} / \mathrm{min}$. Paper chromatography was performed on Whatman 1 paper in a butanol/pyridine/water (6:4:3, v/v) solvent system and alkaline silver nitrate solution was used for staining. The D configurations of glucose, galactosamine, and glucosamine were established using D-glucose oxidase [2], D-galactose oxidase [6], and hexokinase in the presence of ATP [25], respectively. $O$-acetyl groups were determined by the method of Hestrin [10], sialic acid by the resorcinol method [26], Kdo with thiobarbituric acid [12], phosphorus according to Chen et al. [3], and 3-hydroxybutyric acid by the procedure [29] of Williamson and Mellanby.

Methylation was performed according to the procedure of Gunnarsson [9], the methylated products were purified by extraction with chloroform/water $(1: 1, \mathrm{v} / \mathrm{v})$, hydrolyzed with $2 \mathrm{M} \mathrm{CF}_{3} \mathrm{CO}_{2} \mathrm{H}\left(120^{\circ} \mathrm{C}, 2 \mathrm{~h}\right)$ or $10 \mathrm{M} \mathrm{HCl}$ $\left(80^{\circ} \mathrm{C}, 30 \mathrm{~min}\right)$, reduced with $\mathrm{NaBD}_{4}$, acetylated with acetic anhydride in pyridine, and analyzed by GLC-MS as above.

\section{NMR spectroscopy}

Prior to the measurements, the samples were lyophilized twice from $\mathrm{D}_{2} \mathrm{O}$. The ${ }^{1} \mathrm{H}$ - and ${ }^{13} \mathrm{C}-\mathrm{NMR}$ spectra were run on a Bruker DRX-500 spectrometer (Germany) in $99.96 \% \mathrm{D}_{2} \mathrm{O}$ at $50^{\circ} \mathrm{C}$. Chemical shifts were referenced to internal sodium 3-trimethylsilylpropanoate- $\mathrm{d}_{4}\left(\delta_{\mathrm{H}} 0\right)$ and external acetone $\left(\delta_{\mathrm{C}} 31.45\right)$. Mixing times of 100 and $200 \mathrm{~ms}$ were used in 2D total correlation spectroscopy (TOCSY) and rotating frame NOE spectroscopy (ROESY) experiments, respectively.

\section{SDS-PAGE and serological assays}

Preparation of rabbit serum against whole cells of H. alvei PCM 1187 and PCM 537, SDS-PAGE, staining 
of the gels, and immunoblotting were performed as described [14, 19, 27]. A passive hemagglutination test was performed as described previously [8]. LPSs $(1 \mathrm{mg} / 10 \mathrm{ml} \mathrm{PBS})$ were heated $\left(100^{\circ} \mathrm{C}, 2 \mathrm{~h}\right)$ and used to coat horse red blood cells $(0.2 \mathrm{ml}$ of packed cells) at $37^{\circ} \mathrm{C}$ for $1 \mathrm{~h}$. The test was carried out with $1 \%$ erythrocytes and 10-fold dilutions of serum, all in PBS, at $37^{\circ} \mathrm{C}$ for $2 \mathrm{~h}$. Results were expressed as the reciprocal titers of the serum dilutions. Horse erythrocytes were obtained from the Agricultural Academy, (Wrocław, Poland).

\section{RESULTS AND DISCUSSION}

The LPS was extracted from $H$. alvei strain PCM 1219 by the phenol/water procedure in a yield of $6.5 \%$ of dry bacterial mass. SDS-PAGE of the LPS showed a ladder-like pattern of bands typical of smooth strains, which was observed also in immunoblotting with LPS-specific rabbit antiserum (Fig. 1). Immunoblotting revealed strong cross-reactivity with LPS of $H$. alvei type strain PCM 537 (ATCC 13337), but not with several other Hafnia LPSs (not shown). In the passive hemagglutination test, cross-reactivity was observed only for a group of strains related to $H$. alvei strain PCM 537 (Table 1). In order to establish the molecular basis for the serological relationship in this heterogeneous group of strains, the detailed structure of the OPS of $H$. alvei PCM 1219 was examined.

The LPS of $H$. alvei PCM 1219 was degraded by mild acid hydrolysis with $1 \% \mathrm{HOAc}\left(100^{\circ} \mathrm{C}, 1 \mathrm{~h}\right)$, and the supernatant was fractionated on Sephadex G-50 to give nine fractions, indicating the depolymerization of the OPS. When the LPS was degraded with $0.1 \mathrm{M}$ sodium acetate buffer, $\mathrm{pH} 4.2$, at $100^{\circ} \mathrm{C}$ for $4 \mathrm{~h}$, only four frac-
A

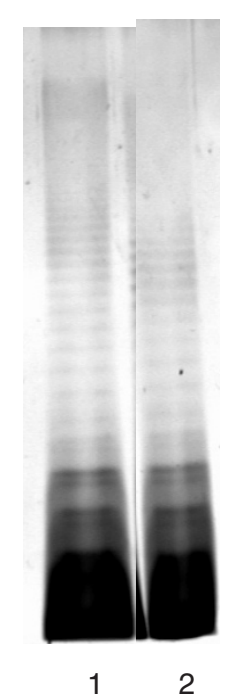

B

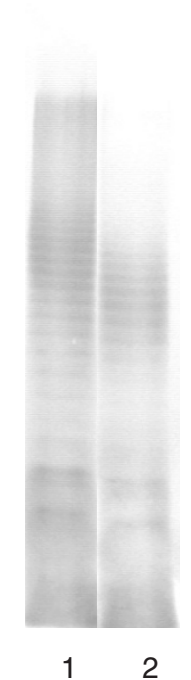

Fig. 1. Silver-stained SDS-PAGE (A) and immunoblotting with anti-H. alvei PCM 537 serum (B) of the LPS from H. alvei PCM 1219 (lane 1) and H. alvei PCM 537 (lane 2).
Table 1. Passive hemagglutination of $H$. alvei LPS with anti-H. alvei PCM 1187 serum

\begin{tabular}{cc}
\hline LPS from strain & Reciprocal titer \\
\hline 1219 & 1280 \\
537 & 1280 \\
1187 & 10240 \\
1194 & 640 \\
744 & 5120 \\
1221 & 5120 \\
\hline
\end{tabular}

tions were obtained, including a longer-chain (OPS) and shorter-chain polysaccharides $\left(\mathrm{P}_{1}\right.$ and $\mathrm{P}_{2}$, respectively), a 3-deoxyoctulosonic acid (Kdo)-containing oligosaccharide (LPS core, $\mathrm{P}_{3}$ ), and free Kdo $\left(\mathrm{P}_{4}\right)$. Fraction $\mathrm{P}_{3}$ was further fractionated on Bio-Gel P-2 to give fractions $\mathrm{P}_{3 \mathrm{a}}$ and $\mathrm{P}_{3 \mathrm{~b}}$.

The search for an acid-labile component (Kdo, sialic acid, glycosyl phosphate) revealed the presence of phosphorus $(2.3 \%)$ in the OPS. Sugar analysis of the OPS by GLC-MS after hydrolysis with $10 \mathrm{M} \mathrm{HCl}$ showed the presence of glucose and galactosamine in a molar ratio of 2.5:2.0. After dephosphorylation of the OPS with $48 \% \mathrm{HF}\left(4^{\circ} \mathrm{C}, 48 \mathrm{~h}\right)$, glucosamine was additionally detected, the molar ratios of glucose, glucosamine, and galactosamine being 2.8:0.8:2.0.

Methylation analysis of the OPS by GLC-MS showed the presence of terminal glucose, 2-substituted glucose, and 3-substituted and 4,6-disubstituted galactosamine residues (Table 2). After dephosphorylation of the OPS followed by methylation analysis including acetylation, the major derivative of terminal glucosamine (3,4,6- $\left.\mathrm{Me}_{3} \mathrm{GlcNAc}\right)$ was also identified together with a trace amount of an N-(3-hydroxybutyryl) derivative $\left(3,4,6-\mathrm{Me}_{3} \mathrm{GlcNAcyl}\right)$. Therefore, the glucosamine derivative in the OPS is phosphorylated and, at least partially, $\mathrm{N}$-acylated with the 3-hydroxybutyryl group. The content of 3-hydroxybutyric acid in the OPS $(0.8 \mu \mathrm{M} / \mathrm{mg})$ was determined by an enzymatic method after hydrolysis of the OPS with $4 \mathrm{M} \mathrm{HC} 1\left(100^{\circ} \mathrm{C}\right.$ for $2.5 \mathrm{~h})$. In addition, the OPS was also found to contain $O$-acetyl groups $(0.38 \mu \mathrm{M} / \mathrm{mg})$ and, hence, is non-stoichiometrically $O$-acetylated.

The structural features of the O-antigen of $H$. alvei PCM 1219, such as the content and substitution pattern of the monosaccharides as well as the presence of a glycosyl phosphate and phosphorylated GlcNAcyl, are similar to those reported earlier for the OPS of $H$. alvei type strain PCM 537 (ATCC 13337) [21]. The similarity was confirmed by methylation analysis data (Table 2) performed on the dephosphorylated OPS from $H$. alvei strains PCM $1219\left(\mathrm{P}_{1} 1219_{\mathrm{HF}}\right), \mathrm{PCM} 537\left(\mathrm{P}_{1} 537_{\mathrm{HF}}\right)$, and PCM $1187\left(\mathrm{P}_{1} 1187_{\mathrm{HF}}\right)$.

The full structure of the OPS from $H$. alvei PCM 1219 was established using ${ }^{1} \mathrm{H}-,{ }^{13} \mathrm{C}$ - (Fig. 2), and ${ }^{31} \mathrm{P}-\mathrm{NMR}$ spectroscopy, including two-dimensional ${ }^{1} \mathrm{H},{ }^{1} \mathrm{H}$ COSY, TOCSY, ROESY, ${ }^{1} \mathrm{H},{ }^{13} \mathrm{C}$ heteronuclear single-quantum coherence (HSQC), and ${ }^{1} \mathrm{H},{ }^{31} \mathrm{P}$ het- 
Table 2. Methylation analysis of the OPS of H. alvei PCM 1219, PCM 537, and PCM 1187

\begin{tabular}{|c|c|c|c|c|c|c|}
\hline \multirow{2}{*}{ Methylated sugar derivative } & \multirow{2}{*}{$\mathrm{T}_{\mathrm{R}}^{\mathrm{a}}$} & \multirow{2}{*}{ Substitution } & \multicolumn{4}{|c|}{ Molar ratio } \\
\hline & & & $\mathrm{P}_{1} 1219$ & $\mathrm{P}_{1} 1219_{\mathrm{HF}}^{\mathrm{b}}$ & $\mathrm{P}_{1} 537_{\mathrm{HF}}^{\mathrm{b}}$ & $\mathrm{P}_{1} 1187_{\mathrm{HF}}^{\mathrm{b}}$ \\
\hline 2,3,4,6-- $\mathrm{Me}_{4} \mathrm{Glc}$ & 1.00 & tGlc & 1.00 & 1.00 & 1.00 & 0.13 \\
\hline 3,4,6- $\mathrm{Me}_{3} \mathrm{Glc}$ & 1.20 & $\rightarrow 2 \mathrm{Glc}$ & 0.90 & 0.34 & 0.23 & 0.04 \\
\hline 3,4,6- $\mathrm{Me}_{3} \mathrm{GlcNAc}$ & 1.68 & tGlcNAc & - & 1.06 & 1.50 & 1.00 \\
\hline $3,6-\mathrm{Me}_{2} \mathrm{GalNAc}$ & 1.89 & $\rightarrow 4 \mathrm{GalNAc}$ & - & - & - & 0.67 \\
\hline 4,6- $\mathrm{Me}_{2} \mathrm{GalNAc}$ & 1.95 & $\rightarrow 3$ GalNAc & 0.40 & 0.46 & 0.75 & 0.38 \\
\hline 3-MeGalNAc & 2.13 & $\rightarrow 4,6 \mathrm{GalNAc}$ & 0.21 & 0.58 & 1.08 & - \\
\hline 3,4,6- $\mathrm{Me}_{3} \mathrm{GlcNAcyl}^{\mathrm{c}}$ & 2.15 & tGlcNAcyl & - & $+^{\mathrm{d}}$ & - & - \\
\hline
\end{tabular}

${ }^{a}$ Retention time in GLC-MS $\left(\mathrm{T}_{\mathrm{R}}\right)$ for the alditol acetate is related to that of 1,5-di- $O$-acetyl-2,3,4,6-tetra- $O$-methyl-glucitol $\left(2,3,4,6-\mathrm{M}_{4} \mathrm{Glc}\right)$. Content of the methylated derivatives of monosaccharides is given as GLC-MS detector response.

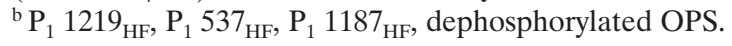

${ }^{\mathrm{c}}$ Acyl stands for the 3-hydroxybutyryl group.

${ }^{\mathrm{d}}$ Compound present in trace amount.

Methylated samples were hydrolyzed with $10 \mathrm{M} \mathrm{HCl}$ at $80^{\circ} \mathrm{C}$ for $30 \mathrm{~min}$.

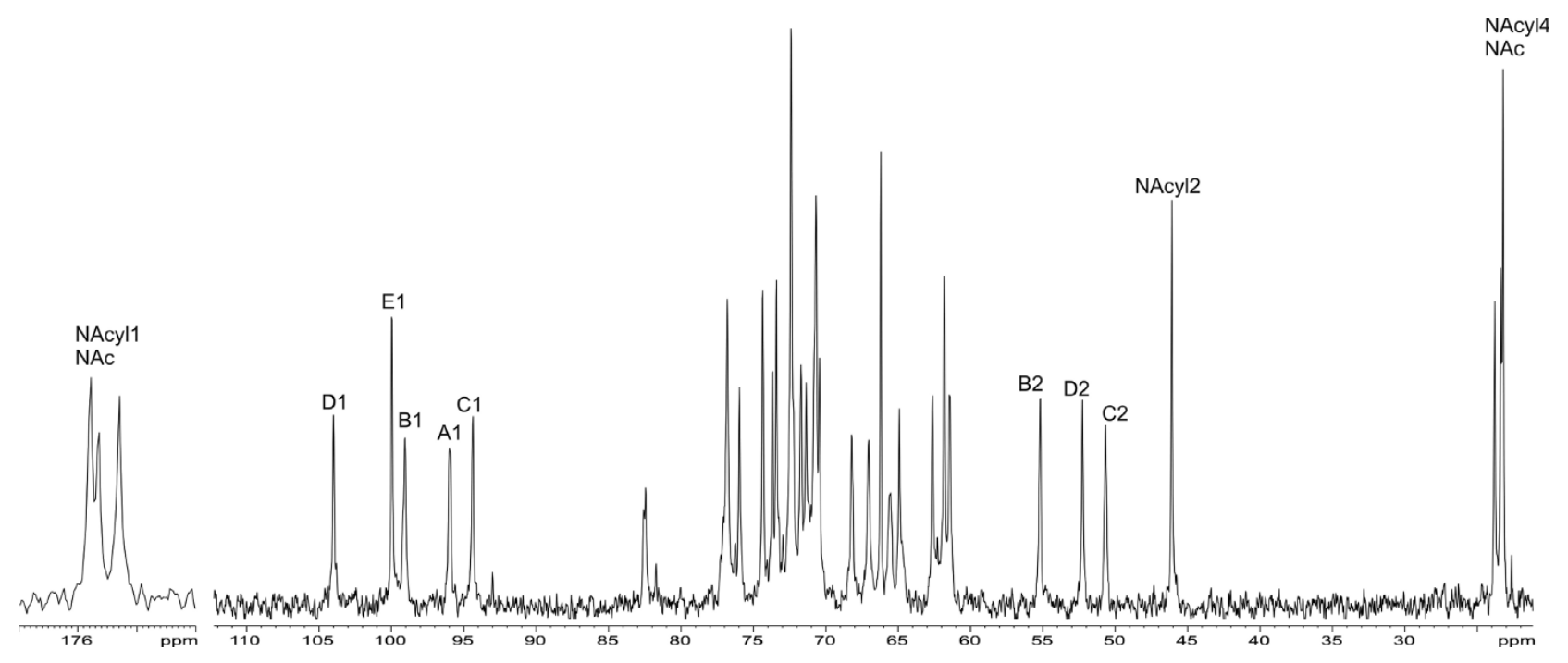

Fig. 2. ${ }^{13}$ C NMR spectrum of the O-polysaccharide of H. alvei PCM 1219. Numerals refer to carbons in the sugar residues denoted as shown in Table 3. NAc, N-acetyl groups; NAcyl, N-3-hydroxybutyryl groups.

eronuclear multiple-quantum coherence (HMQC) experiments according to the published methodology [5]. Based on the assigned chemical shifts given in Table 3, the glycosylation and phosphorylation patterns in the $O$-deacetylated polysaccharide were defined using $\mathrm{H}$-detected ${ }^{1} \mathrm{H},{ }^{13} \mathrm{C}$ HSQC and ${ }^{1} \mathrm{H},{ }^{31} \mathrm{P}$ HMQC data. The sequence of the monosaccharides in the repeating unit was determined by a ROESY experiment, which showed correlations between the anomeric protons and protons at the linkage carbons. Finally, the presence of an $O$-acetyl group at position 3 of GlcNAcyl was established by a comparison of the ${ }^{1} \mathrm{H},{ }^{13} \mathrm{C}$ HSQC spectra of the initial OPS and $O$-deacetylated polysaccharide and, based on integral intensities ratios of ${ }^{1} \mathrm{H}-\mathrm{NMR}$ signals of the nonacetylated and 3-O-acetylated GlcNAcyl residues, the degree of $O$-acetylation was estimated as $\sim 70 \%$

The data obtained showed that the O-antigen of
H. alvei 1219 has the same structure as those of $H$. alvei PCM 537 (ATCC 13337) and 114/60, including the position and degree of $O$-acetylation (structure 1 in Fig. 3). The O-antigens from related strains, including $H$. alvei 1194, 744, and PCM 1221, differ in the absence of $O$-acetyl groups (structure 2). The O-antigen of yet another, more distantly related strain, H. alvei PCM 1187 , is devoid of both $O$-acetyl groups and the lateral glucose residue (structure 3). Therefore, H. alvei PCM 1219 is already the seventh representative of the group of strains with identical or similar O-antigen structures (Fig. 3) and all these strains should be classified in the same serogroup.

As for the majority of $H$. alvei strains studied so far $[16,21]$, methylation analysis of the core oligosaccharide fractions $\mathrm{P}_{3 \mathrm{a}}$ and $\mathrm{P}_{3 \mathrm{~b}}$ from $H$. alvei PCM 1219 revealed terminal and 3-substituted glucose as well as terminal heptose residues, and after dephosphorylation also 3- 
Table 3. ${ }^{1} \mathrm{H}$ and ${ }^{13} \mathrm{C}$ NMR chemical shifts $(\delta$, ppm) of the $O$-deacetylated polysaccharide from $H$. alvei PCM 1219

\begin{tabular}{|c|c|c|c|c|c|c|c|c|}
\hline & \multirow{2}{*}{ Residue } & \multicolumn{7}{|c|}{ Atom } \\
\hline & & $\mathrm{H}-1$ & $\mathrm{H}-2$ & $\mathrm{H}-3$ & H-4 & H-5 & H-6 & H-6' \\
\hline $\mathbf{A}$ & $\rightarrow 2)-\alpha-\mathrm{D}-\mathrm{Glc} p-1-P-\left(\mathrm{O} \rightarrow^{\mathrm{a}}\right.$ & 5.79 & 3.63 & 3.85 & 3.53 & 3.84 & 3.91 & 3.70 \\
\hline B & $-6)-\alpha-D-G l c p N A c y l-\left(1 \rightarrow^{b}\right.$ & 4.99 & 4.01 & 3.87 & 3.65 & 4.31 & 4.18 & 4.05 \\
\hline $\mathbf{C}$ & $\begin{array}{c}\rightarrow 4)-\alpha-D-G a l p N A c-\left(1 \rightarrow^{c}\right. \\
6 \\
\uparrow\end{array}$ & 5.15 & 4.32 & 3.93 & 4.17 & 4.03 & 3.85 & 3.66 \\
\hline D & $\rightarrow 3)-\beta-\mathrm{D}-\mathrm{Gal} p \mathrm{NAc}-\left(1 \rightarrow^{\mathrm{c}}\right.$ & 4.72 & 4.11 & 3.82 & 4.09 & 3.65 & 3.83 & 3.83 \\
\hline \multirow[t]{2}{*}{$\mathbf{E}$} & $\alpha-\mathrm{D}-\mathrm{Glcp}-(1 \rightarrow$ & 4.88 & 3.59 & 3.68 & 3.48 & 3.66 & 3.87 & 3.79 \\
\hline & & $\mathrm{C}-1$ & $\mathrm{C}-2$ & $\mathrm{C}-3$ & $\mathrm{C}-4$ & $\mathrm{C}-5$ & C-6 & \\
\hline $\mathbf{A}$ & $\rightarrow 2)-\alpha-\mathrm{D}-\mathrm{Glc} c-1-P-\left(\mathrm{O} \rightarrow^{\mathrm{b}}\right.$ & 96.0 & 82.4 & 73.9 & 70.6 & 72.7 & 62.7 & \\
\hline B & $-6)-\alpha-D-G l c p N A c y l-\left(1 \rightarrow^{\mathrm{d}}\right.$ & 99.2 & $55.2^{\mathrm{c}}$ & 71.9 & 71.0 & 72.5 & 65.8 & \\
\hline $\mathbf{C}$ & $\begin{array}{c}\rightarrow 4)-\alpha-\mathrm{D}-\mathrm{Gal} p \mathrm{NAc}-\left(1 \rightarrow^{\mathrm{e}}\right. \\
6 \\
\uparrow\end{array}$ & 94.6 & 50.8 & 68.4 & 76.9 & 71.6 & 67.4 & \\
\hline D & $\rightarrow 3)-\beta-\mathrm{D}-\mathrm{Gal} p \mathrm{NAc}-\left(1 \rightarrow^{\mathrm{e}}\right.$ & 104.0 & 52.5 & 76.1 & 65.2 & 76.9 & 61.7 & \\
\hline $\mathbf{E}$ & $\alpha-\mathrm{D}-\mathrm{Glc} p-(1 \rightarrow$ & 100.2 & 72.7 & 74.5 & 70.8 & 73.6 & 62.0 & \\
\hline
\end{tabular}

Letters A-E refer to formula 1 in Fig. 3.

${ }^{\text {a }}$ A signal for ${ }^{31} \mathrm{P}$ is at $-0.7 \mathrm{ppm}$.

${ }^{\text {b }}$ Signals for 3-hydroxybutyryl (Acyl) are at 2.53 (H-2), 4.23 (H-3), and $1.30(\mathrm{H}-4) \mathrm{ppm}$.

${ }^{\mathrm{c}}$ Signals for NAc are at 2.03 and $2.05 \mathrm{ppm}$.

d Signals for 3-hydroxybutyryl (Acyl) are at 176.1 (C-1), 46.3 (C-2), 66.2 (C-3), and 23.3 (C-4) ppm.

${ }^{\mathrm{e}}$ Signals for NAc are at 23.8, $24.0\left(\right.$ both $\left.\mathrm{CH}_{3}\right), 175.6$, and 176.1 (both $\left.\mathrm{CO}\right) \mathrm{ppm}$.

H. alvei PCM 537 (ATCC 13337), 114/60, PCM 1219

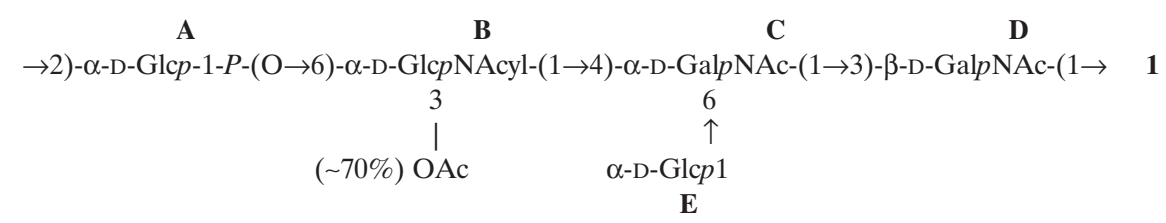

H. alvei 1194, 744, РCM 1221

$\rightarrow 2)-\alpha-\mathrm{D}-\mathrm{Glc} p-1-P-(\mathrm{O} \rightarrow 6)-\alpha-\mathrm{D}-\mathrm{Gl} p \mathrm{NAcyl}-(1 \rightarrow 4)-\alpha-\mathrm{D}-\mathrm{Gal} p$ NAc- $(1 \rightarrow 3)-\beta-\mathrm{D}-\mathrm{Gal} p \mathrm{NAc}-(1 \rightarrow \quad 2$
6
$\uparrow$
$\alpha$-D-Glc 1

H. alvei PCM 1187

$\rightarrow 2)-\alpha-D-G l c p-1-P-(\mathrm{O} \rightarrow 6)-\alpha-D-G l c p N A c y l-(1 \rightarrow 4)-\alpha-D-G a l p N A c-(1 \rightarrow 3)-\beta-D-G a l p N A c-(1 \rightarrow \quad 3$

Fig. 3. Structures of the OPS from H. alvei PCM 1219 (this work) and related O-polysaccharides [21]. Acyl stands for the 3-hydroxybutyryl group. -substituted and 3,7-disubstituted heptose residues. The presence of the typical $H$. alvei LPS core is in accordance with the classification of strain PCM 1219 within the genus Hafnia.

\section{REFERENCES}

1. Baturo A. P. and Raginskaya V. P. (1978): Antigenic scheme for the Hafniae. Int. J. Syst. Bacteriol., 28, 126-127.

2. Bergmeyer H. U. and Bernt E. (1974): Determination of D-glucose with glucose oxidase and peroxidase. In Bergmeyer H U. (ed.): Methods of Enzymatic Analysis. New York, Academic Press, pp. 1205-1215.

3. Chen P. S., Toribara T. Y. and Warner H. (1956): Microdetermination of phosphorus. Anal. Chem., 28, 1756-1758.
4. Dubois H., Gilles K. A., Hamilton J. K., Rebers P. and Smith F. (1956): Colorimetric method for determination of sugars and related substances. Anal. Chem., 28, 350-356.

5. Duus J. O., Gotfredsen C. H. and Bock K. (2000): Carbohydrate structural determination by NMR spectroscopy: Modern methods and limitations. Chem. Rev., 100, 4589-4614.

6. Fischer W. and Zapf J. (1964): The quantitative determination of galactose by means of galactose oxidase from Dactylium dendroides. Hoppe Seylers Z. Physiol. Chem., 337, 186-195.

7. Gamian A., Romanowska E., Dabrowski U. and Dabrowski J. (1991): Structure of the O-specific, sialic acid containing polysaccharide chain and its linkage to the core region in lipopolysaccharide in Hafnia alvei strain 2 as elucidated by chemical methods, gas-liquid chromatography/mass spectrometry. Biochemistry, 30, 5032-5038. 
8. Gamian A., Romanowska A. and Romanowska E. (1992): Immunochemical studies on sialic acid-containing lipopolysaccharides from enterobacterial species. FEMS Microbiol. Immunol., 89, 323-328.

9. Gunnarsson A. (1987): N- and O-Alkylation of glycoconjugates and polysaccharides by solid base in dimethyl sulphoxide/alkyl iodide. Glycoconjug. J., 4, 239-245.

10. Hestrin S. (1949): The reaction of acetylcholine and other carboxylic acid derivatives with hydroxylamine, and its analytical application. J. Biol. Chem., 180, 249-261.

11. Janda J. M. and Abbott S. L. (2006): The genus Hafnia: from soup to nuts. Clin. Microbiol. Rev., 19, 12-18.

12. Karkhanis Y. A., Zeltner, J. Y., Jackson J. J. and Carlo D. J. (1978): A new and improved microassay to determine 2-keto-3-deoxyoctonate in lipopolysaccharide of Gram-negative bacteria. Anal. Biochem., 85, 595-601.

13. Katzenellenbogen E., Kocharova N. A., Zatonsky G. V., Bogulska M., Korzeniowska-Kowal A., Shashkov A. S., Gamian A., Bogulska M. and Knirel Y.A. (2005): Structure of the O-polysaccharide of Hafnia alvei strain PCM 1189 that has hexa- to octa-saccharide repeating units owing to incomplete glucosylation. Carbohydr. Res., 340, 263-270.

14. Katzenellenbogen E., Kocharova N. A., Zatonsky G. V., Kübler-Kiełb J., Gamian A., Shashkov A. S., Knirel Y. A. and Romanowska E. (2001): Structural and serological studies on Hafnia alvei O-specific polysaccharide of $\alpha$-D-mannan type isolated from the lipopolysaccharide of strain PCM 1223. FEMS Immunol. Med. Microbiol., 30, 223-227.

15. Katzenellenbogen E., Kocharova N. A., Zatonsky G. V., Mieszala M., Gamian A., Bogulska M., Shashkov A. S., Romanowska E. and Knirel Y. A. (1998): Immunochemical studies of the lipopolysaccharide O-specific polysaccharide of Hafnia alvei PCM 1199 related to $H$. alvei PCM 1205. Eur. J. Biochem., 251, 980-985.

16. Katzenellenbogen E., Kocharova N. A., Zatonsky G. V., Shashkov A. S., Bogulska M. and Knirel Y. A. (2005): Structures of the biological repeating units in the O-chain polysaccharides of Hafnia alvei strains having a typical lipopolysaccharide outer core region. FEMS Immunol. Med. Microbiol., 45, 269-278.

17. Katzenellenbogen E., Romanowska E., Witkowska D. and
Shashkov A. S. (1992): The structure of the O-specific polysaccharide from Hafnia alvei strain 38 lipopolysaccharide. Carbohydr. Res., 231, 51-54.

18. Klapholz A., Lessnau K. D., Huang B., Talavera W. and Boyle J. F. (1994): Hafnia alvei. Respiratory tract isolates in a community hospital over a three-year period and a literature review. Chest, 105, 1098-1100.

19. Laemmli U. K. (1970): Cleavage of structural proteins during the assembly of the head of bacteriophage T4. Nature, 227, 680-685.

20. Romanowska E. (1970): Sepharose gel filtration method of purification of lipopolysaccharides. Anal. Biochem., 33, 383-389.

21. Romanowska E. (2000): Immunochemical aspects of Hafnia alvei O-antigens. FEMS Immunol. Med. Microbiol., 27, 219-225.

22. Romanowska E. and Mulczyk M. (1968): Chemical studies on the specific fragment of Shigella sonnei phase II. Eur. J. Biochem., 5, 109-113.

23. Sakazaki R. and Tamura K. (1992): The genus Hafnia. In Balows A., Trüper H. G., Dworkin M., Harder W. and Schleifer K.-H. (eds.): The Prokaryotes. Springer Verlag, New York, vol. 3, pp. 2816-2821.

24. Sawardeker J. S., Sloneker J. H. and Jeanes A. (1965): Quantitative determination of monosaccharides as their alditol acetates by gas liquid chromatography. Anal. Chem., 37, 1602-1603.

25. Sturgeon R. J. (1980): Enzymic determination of D-glucose, D-fructose, and D-mannose. Methods Carbohydr. Chem., 8, 135-137.

26. Svennerholm L. (1957): Quantitative estimation of sialic acids. II. A colorimetric resorcinol-hydrochloric acid method. Biochim. Biophys. Acta, 24, 604-611.

27. Tsai C. M. and Frash C. E. (1982): A sensitive silver stain for detecting of lipopolysaccharides in polyacrylamide gels. Anal. Biochem., 119, 115-119.

28. Westphal O. and Jann K. (1965): Bacterial lipopolysaccharides: extraction with phenol-water and further applications of the procedure. Methods Carbohydr. Chem., 5, 83-91.

29. Williamson D. H. and Mellanby J. (1974): D(-|-)3-hydroxybutyrate. In Bergmeyer H. U. (ed.): Methods of Enzymatic Analysis. Academic Press, New York, pp. 1836-1839. 